\title{
Point of Care Ultrasound Training during the Coronavirus Disease 2019 Pandemic
}

\author{
Kamonwon lenghong ${ }^{1}$, Takaaki Suzuki $^{2}$, Somsak Tiamkao ${ }^{3}$, Vajarabhongsa Bhudhisawasdi ${ }^{1}$, Dhanu Gaysonsiri ${ }^{4}$, \\ Korakot Apiratwarakul ${ }^{1 *}$ (if \\ ${ }^{1}$ Department of Emergency Medicine, Faculty of Medicine, Khon Kaen University, Khon Kaen, Thailand; ${ }^{2}$ Department of \\ Emergency and Critical Care Medicine, University of Tsukuba Hospital, Tsukuba, Japan; ${ }^{3}$ Department of Medicine, Faculty \\ of Medicine, Khon Kaen University, Khon Kaen, Thailand; ${ }^{4}$ Department of Pharmacology, Faculty of Medicine, Khon Kaen \\ University, Khon Kaen, Thailand
}

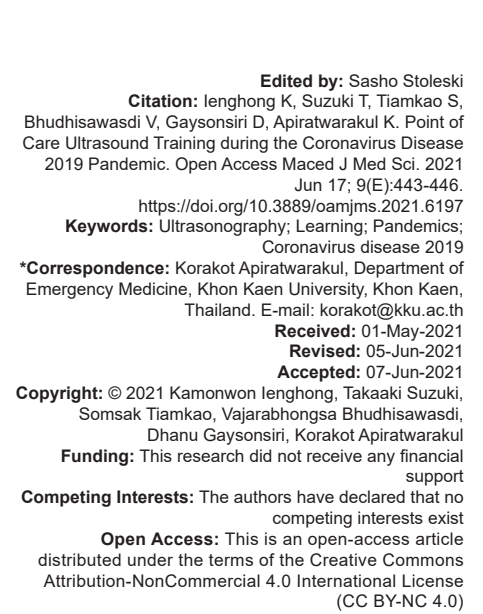

\section{Introduction}

Proper administering of a point of care ultrasound (POCUS) is one of the most essential skills for emergency physicians to have. Hence, POCUS training is part of the core competency in the training of emergency medicine (EM) residents required in many countries, including both developed and developing countries [1], [2], [3], [4], [5]. In 2019, we implemented the ultrasound (US) rotation for $1^{\text {st }}$-year EM residents. The POCUS curriculum for the EM residents was conducted over a 2 week period. The course content included didactic lectures, bedside US training with actual patients, the journal club, and the image review process. However, like most everything else, the POCUS training was interrupted by the coronavirus disease 2019 (COVID-19) pandemic, which The World Health Organization declared on March 11, 2020. In Thailand, the Prime Minister declared a state of emergency, effective on 26 March. At that time, medical training in Thailand was forced to drastically change on-site training, the faculty, and almost all international exchange programs.

Innovations and adjustments of POCUS training during the COVID-19 pandemic have been developed, for example, Tele - US, video-conferencing [6], virtual POCUS courses [7], and personal handheld USs [8]. Our POCUS training curriculum was changed in the beginning of 2020 to be carried out as virtual learning. In this study, we aimed to measure and evaluate the EM residents' POCUS knowledge and skills development during the COVID-19 pandemic after having completed their training.

\section{Methods}

\section{Study design}

This was a retrospective, single-centered, and observational study at a tertiary university hospital in 
Thailand. Ethical approval was provided by the Khon Kaen University Ethics Committee for Human Research (HE641218).

\section{Sample size}

The $1^{\text {st }}$-year EM residents, who were taking part in the US rotation at the Department of EM at Khon Kaen University's Srinagarind Hospital during the 2019-2020 Academic year, were enrolled in this study. The EM residents, who had not participated in this rotation, were excluded. Hence, the total number of participants was determined to be 18 EM residents which were divided into two groups of 9 participants per academic year.

\section{Study protocol \\ POCUS training in the US rotation}

For the 2019 academic year, there was a 2-week rotation in the Emergency Department. The number of residents in training was 9. During this period, bedside US learning with real patients (9 h/week) was conducted by a supervisor, who was a POCUS specialist. In addition, residents participated in the journal club ( 1 session, $3 \mathrm{~h}$ ), the process of reviewing the US images ( 1 session, $3 \mathrm{~h}$ ), and the didactic lectures ( $3 \mathrm{~h} /$ week).

For the 2020 academic year, participants were provided the POCUS training in a different manner than that of 2019. The duration and the number of residents in training in this rotation were the same as for the 2019 academic year. The didactic lecture, the journal club, and the process US image review were carried out as virtual conferences via various platforms, including the ZOOM and LINE CALL applications. The bedside US learning was not provided due to the difficult task of trying to deliver the lesson safely.

\section{The POCUS training evaluation}

All of the participants were required to complete the pre-training and post-training tests which consisted of 10 POCUS multiple-choice questions. At the end of the rotation, we arranged a US skills test during which all participants performed the POCUS with a healthy volunteer. The residents received written instructions about what task to perform and what to document. The main requirement was that the exam had to be completed in 15 min or less. A checklist was used and each exam component was assessed using the (global rating scale [GRS]; 1 = Poor, 5 = Excellent). The US skills of the participants were evaluated in accordance with 4 items, which included the aspects of image acquisition, target identification, image interpretation, and US knowledge.

In addition, in the 2020 academic year, we also asked that the participants complete a survey meant to gather their perceptions of the events. The participants received an anonymous electronic survey that utilized 5 -Likert scores. The survey included questions about the learner's opinions about the value of the training in light of his/her own personal development and allowed for open-ended feedback. The anonymous survey responses were then analyzed.

\section{Statistical analysis}

The quantitative data were presented as means \pm standard deviations, while the qualitative data were presented using proportions and percentages. Differences in the pre-training and post-training tests were compared using a paired sample t-test. A two-tailed $p<0.05$ was considered to be statistically significant. All data analyses were performed using Stata version 10 (StataCorp, College Station, TX).

\section{Results}

From 2019 to 2020 academic year, this study included $181^{\text {st }}$-year EM residents, all of which completed the test. The average pre-training score and post-training scores are shown in Figure 1.

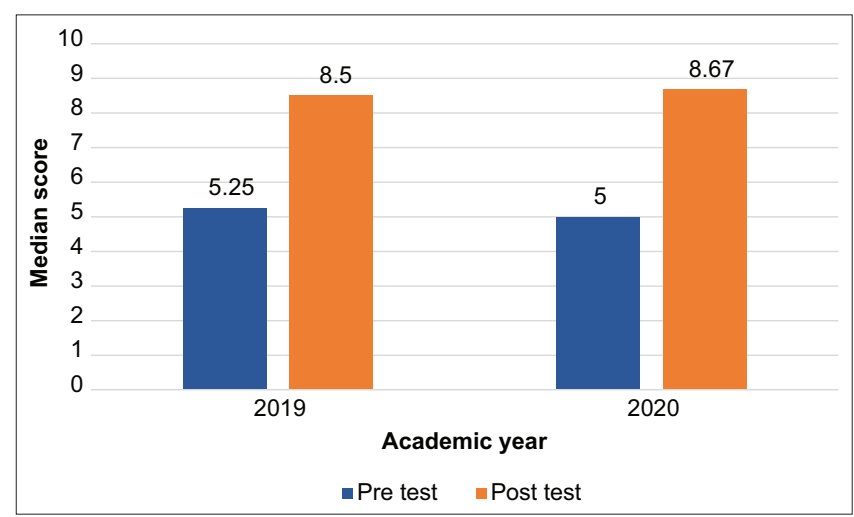

Figure 1: Average score of pre- and post-training scores followed by academic year

In terms of the US skills test, the total average scores in the 2019-2020 academic year were 17 out of $20(85 \%)$ and 14.875 out of $20(74.38 \%)$, respectively $(p<0.001)$ (Table 1).

Table 1: Median scores of US skills test derived by academic year

\begin{tabular}{llll}
\hline Items & \multicolumn{2}{l}{ Scores (Median) (\%) } & p-value \\
\cline { 2 - 3 } & 2019 & 2020 & \\
\hline Image acquisition & $4.125(82.5)$ & $3.5(70)$ & $<0.001$ \\
Target identification & $4.125(82.5)$ & $3(60)$ & $<0.001$ \\
Image interpretation & $4.375(87.5)$ & $4(80)$ & $<0.001$ \\
US knowledge & $4.375(87.5)$ & $4.375(87.5)$ & 1.000 \\
\hline US: Ultrasound. & & &
\end{tabular}

In regards to the survey questions about the residents' opinions of virtual learning, the total average score was 19.75 out of 25 (79\%). In terms of the openended feedback, participants reported that the virtual 
learning had some obstacles, including internet access, internet instability, availability of a computer or mobile device, eye fatigue from long hours of digital uses, and the lack of practice with a real patient or in a real situation (Table 2).

Table 2: The average score of survey question

\begin{tabular}{ll}
\hline Survey questions & Scores (Median) (\%) \\
\hline Students' interest for virtual learning & $4.5(90)$ \\
Adequate study materials available online & $4.75(95)$ \\
Teacher-student interaction is better in online platforms than & $3(60)$ \\
through traditional learning & \\
Online platforms can improve US knowledge & $4.5(90)$ \\
Online platforms can improve the confidence to scan real patients & $3(60)$ \\
\hline US: Ultrasound.
\end{tabular}

\section{Discussion}

Our results demonstrated that the pre-and posttraining scores were no different among the participants who had learned by the traditional classroom method and those that used online platforms. This suggested that the online platform, which was developed in the 2020 academic year, had been successful in improving their POCUS knowledge, which was consistent with previous studies [8], [9], [10], [11]. It also showed that the vast array of resources available can be incorporated into lessons, that is, books, online texts, the internet, social media, podcasts, etc., allow participants to study anywhere.

However, the establishment of one's own skills requires a period of practice and practical, hands-on experience. As the results of our study have shown, the participants who learned using online platforms had lower US skills test scores than those of the theoretical test, which was consistent with the previous studies [8], [12], [13]. Due to the COVID-19 outbreak, this was a major change in the education process and a full step into a digital society [12] where previous efforts have been made to transform the educational process from memorization to studentcentered learning. With the constraints of the social distancing policy, teachers had to, with very little time, create a new paradigm for the entire online teaching of theories. As for practical teaching, it is challenging for teachers to adjust strategies so that learners can more easily understand and also develop practical skills [12], [13], [14].

The results of the surveys demonstrated that the participants rated higher scores in the aspect of students' interests, online learning materials, and the effectiveness of improving US knowledge using virtual studies which were consistent with previous studies [8]. However, our results showed that the participants were in agreement that virtual learning was not as good as on-site learning in terms of interactive discussion. In addition, the virtual learning could not contribute to the confidence of the participants to perform a US on real patients, which was consistent with the US skills score from our results. The most important obstacle for virtual learning in this study was internet instability and the insufficient number of devices to access the internet, which was consistent with the previous studies [8]. Therefore, the faculty should be prepared to face this issue before transforming fully to digital learning.

The limitations of our study [15], [16], [17], [18], [19] were that it was performed in a single country with specific settings. Therefore, the results may not be generalized when considering other countries. However, our results demonstrated the same obstacles of the virtual or online learning that we mentioned above, which can be useful in preparation for conducting any online courses.

\section{Conclusions}

Our findings indicated that the participants can greatly improve US knowledge through virtual learning. Moreover, the overall attitude toward using this type of learning in our participants was quite positive. However, this learning technique was not suitable for teaching practical skills, including the actual administering of a US.

\section{Acknowledgments}

The authors would like to thank all participants in this study as well as Josh Macknick, for acting as an English consultant.

\section{References}

1. American Board of Emergency Medicine. The Emergency Medicine Milestone Project. East Lansing, MI: Accreditation Council for Graduate Medical Education, American Board of Emergency Medicine; 2007.

2. Rouhani SA, Israel K, Leandre F, Pierre S, Bollman B, Marsh RH Addressing the immediate need for emergency providers in resource-limited settings: The model of a six-month emergency medicine curriculum in Haiti. Int J Emerg Med. 2018;11(1):22. https://doi.org/10.1186/s12245-018-0182-y PMid:29626265

3. Aluisio AR, Barry MA, Martin KD, Mbanjumucyo G, Mutabazi ZA, Karim $\mathrm{N}$, et al. Impact of emergency medicine training implementation on mortality outcomes in Kigali, Rwanda: An interrupted time-series study. Afr J Emerg Med. 2019;9(1):1420. https://doi.org/10.1016/j.afjem.2018.10.002

PMid:30873346 
4. Meshkat N, Teklu S, Hunchak C, TAAAC-EM and the Global Health Emergency Medicine (GHEM) Organization at the Division of Emergency Medicine, University of Toronto. Design and Implementation of a postgraduate curriculum to support Ethiopia's first emergency medicine residency training program: The Toronto Addis Ababa Academic Collaboration in Emergency Medicine (TAAAC-EM). BMC Med Educ. 2018;18(1):71. https:// doi.org/10.1186/s12909-018-1140-3

PMid:29625563

5. Tafoya CA, Tafoya MJ, Osei-Ampofo M, Oteng RA, Becker TK Sustainable resuscitation ultrasound education in a low-resource environment:The Kumasiexperience.JEmerg Med. 2017;52(5):72330. https://doi.org/10.1016/j.jemermed.2017.01.050

PMid:28284769

6. Eke OF, Henwood PC, Wanjiku GW, Fasina A, Kharasch SJ Shokoohi H. Global point-of-care ultrasound education and training in the age of COVID-19. Int J Emerg Med. 2021;14(1):12. https://doi.org/10.1186/s12245-021-00338-9 PMid:33602112

7. Lin SD. A virtual point-of-care ultrasound course during the COVID-19 pandemic. AEM Educ Train. 2020;5(1):102-4. PMid:33230494

8. Alsoufi A, Alsuyihili A, Msherghi A, Elhadi A, Atiyah H, Ashini A, et al. Impact of the COVID-19 pandemic on medical education: Medical students' knowledge, attitudes, and practices regarding electronic learning. PLoS One. 2020;15(11):e0242905. https:// doi.org/10.1371/journal.pone.0242905

PMid:33237962

9. Noble VE, Nelson BP, Sutingco AN, Marill KA, Cranmer H. Assessment of knowledge retention and the value of proctored ultrasound exams after the introduction of an emergency ultrasound curriculum. BMC Med Educ. 2007;7:40. https://doi. org/10.1186/1472-6920-7-40

PMid:17971234

10. Kelm DJ, Ratelle JT, Azeem N, Bonnes SL, Halvorsen AJ, Oxentenko AS, et al. Longitudinal ultrasound curriculum improves long-term retention among internal medicine residents. J Grad Med Educ. 2015;7:454-7. https://doi.org/10.4300/ jgme-14-00284.1

PMid:26457155
11. Nassour I, Spalding MC, Hynan LS, Gardner AK, Williams BH The surgeon-performed ultrasound: A curriculum to improve residents' basic ultrasound knowledge. J Surg Res. 2017;213:51 9. https://doi.org/10.1016/j.jss.2017.02.031 PMid:28601332

12. Lucey CR, Johnston SC. The transformational effects of COVID-19 on medical education. JAMA. 2020;324(11):1033-4. https://doi.org/10.1001/jama.2020.14136 PMid:32857137

13. Rose S. Medical student education in the time of COVID-19. JAMA. 2020;323(21):2131-2. https://doi. org/10.1001/jama.2020.5227 PMid:32232420

14. Ahmed $\mathrm{H}$, Allaf $\mathrm{M}$, Elghazaly $\mathrm{H}$. COVID-19 and medical education. Lancet Infect Dis. 2020;20(7):777-8. https://doi. org/10.1016/s1473-3099(20)30226-7 PMid:32213335

15. Apiratwarakul $\mathrm{K}$, Songserm $\mathrm{W}$, lenghong $\mathrm{K}$, Phungoen $\mathrm{P}$, Gaysonsiri D, Bhudhisawasdi V. The role of mechanical cardiopulmonary resuscitation devices in emergency medical services. J Med Assoc Thai. 2020;103 Suppl 6:98-101.

16. lenghong $\mathrm{K}$, Kotruchin $\mathrm{P}$, Tangpaisarn $\mathrm{T}$, Apiratwarakul $\mathrm{K}$. Practical emergency ultrasound flashcards with augmented reality in teaching point-of-care ultrasound in ER. Open Access Maced J Med Sci. 2021;9(E):39-42. https://doi.org/10.3889/ oamjms.2021.5566

17. Apiratwarakul $K$, lenghong $K$, Gaysonsiri $D$, Mitsungnern $T$, Buranasakda M, Bhudhisawasdi V. The effectiveness of oxygen-powered inhalation devices in prehospital care. J Med Assoc Thai. 2020;103 Suppl 6:58-60.

18. lenghong $\mathrm{K}$, Jumroenketpratheep $\mathrm{K}$, Tiamkao $\mathrm{S}$, Apiratwarakul $\mathrm{K}$. Use of handheld versus standard ultrasound devices in ultrasound rotation at the emergency department. Open Access Maced J Med Sci. 2021;9(E):29-32. https://doi. org/10.3889/oamjms.2021.5528

19. lenghong K, Kleebbuakwan K, Apiratwarakul K, Phungoen $\mathrm{P}$, Gaysonsiri D, Bhudhisawasdi V. Comparison of cleaning methods for ultrasound probes at an emergency department in a resource-limited country. J Med Assoc Thai. 2020;103 Suppl 6:67-71. 